\title{
Promotionalism, Motivationalism and Reasons to Perform Physically IMPOSSIBLE ACTIONS
}

NOTE: This is a draft version of the paper that is due to appear in Ethical Theory and Moral Practice in 2012. The final publication is (or soon will be) available at www.springerlink.com

\begin{abstract}
In this paper I grant the Humean premise that some reasons for action are grounded in the desires of the agents whose reasons they are. I then consider the question of the relation between the reasons and the desires that ground them. According to promotionalism, a desire that $p$ grounds a reason to $\varphi$ insofar as A's $\varphi$ ing helps promote $p$. According to motivationalism a desire that $p$ grounds a reason to $\varphi$ insofar as it explains why, in certain circumstances, A would be motivated to $\varphi$. I then give an argument favouring motivationalism, namely that promotionalism entails that agents have reasons to perform physically impossible actions, whereas motivationalism entails that there are no such reasons. Although this is a version of the "Too Many Reasons' objection to promotionalism, I show that existing responses to that problem do not transfer to the case of reasons to perform physically impossible actions. In the penultimate section I consider and reject some objections to motivationalism made my promotionalists. The conclusion is that Humeans about reasons for action should prefer motivationalism.
\end{abstract}

\section{Two Accounts of the Relation between Reasons and Desires}

Suppose, as Hume perhaps thought, that some reasons for action are based in desires. ${ }^{1}$ How so? There are at least two ways in which a particular agent's desire that $p$ might ground (or explain) a reason for that agent to perform some act $\varphi .{ }^{2}$ On the first view - call it

\footnotetext{
${ }^{1}$ I will follow Williams (1981) and Schroeder (2007) in construing 'desire' broadly to cover any suitable motivational state. All that the following discussion requires is that such states be understandable as embodying a goal expressible in propositional form and that they can explain agents' motivations. For the sake of readability, I will sometimes express the contents of desires using the 'desire to...' locution rather than the propositional 'desire that...' form. In so doing, I make the common assumption that the contents of desires can always be expressed in the latter way (although see Alverez 2010 for doubts). On the issue of Hume's own views, see Setiya 2004.

${ }^{2}$ A third option, a popular characterisation of Humean views by opponents, is that desires ground reasons insofar as desires themselves are parts of reasons (or, more precisely, reason-giving facts). Schroeder calls this the 'no background conditions' view (2007: 23-40). One problem is that it is objectionably self-regarding: given that reasons are what one deliberates about when one reasons well, this view entails that practical reasoning
} 
promotionalism - agent A's desire that $p$ grounds a reason to $\varphi$ insofar as A's $\varphi$ ing helps promote $p$. Schroeder has defended a view of this kind. He claims:

For all propositions $r$, agents $\mathrm{A}$ and actions $\varphi, r$ is a reason for $\mathrm{A}$ to $\varphi$ if and only if there is some $p$ such that $\mathrm{A}$ has a desire whose object is $p$, and the truth of $r$ is part of what explains why A's doing $\varphi$ promotes $p$. (Schroeder 2007: 57. See also Brandt 1979. $)^{3}$

According to Schroeder, A's ping promotes $p$ just in case A's $\varphi$ ing increases the likelihood of $p$ relative to the baseline of A's doing nothing (2007: 113). Consider Schroeder's own example. Bradley desires that he strut his stuff on the dance floor. The fact that there is dancing at the party is reason for Bradley to go to the party because this fact explains why Bradley's going to the party raises the likelihood of him strutting his stuff (one cannot strut alone). ${ }^{4}$

On a second view - call it motivationalism - A's desire that $p$ grounds a reason to $\varphi$ insofar as it explains why, in some particular circumstances, A would be motivated to $\varphi$. Goldman has recently defended a view of this kind. He claims:

A has an F-reason $r$ to do act $\varphi$ iff. A is F-minded and, because of that, if rational, would be motivated by awareness of $r$ to do $\varphi$. (2009: 34; see also Williams 1981.) $)^{5}$

focuses at least in part on one's own psychological states (Schroeder 2007: 26-7). Another problem with considering this view in the current context is that no prominent defender of a Humean view seems to hold it.

${ }^{3}$ Schroeder (2007) labels his view Hypotheticalism, but includes under that label particular views of the nature of desire and the weight of reasons. As I understand it, promotionalism is purely a view about how desires ground reasons.

${ }^{4}$ A stronger view of the promotion relation holds that A's $\varphi$ ing promotes $p$ iff. A's $\varphi$ ing is a necessary means to the realisation of $p$. The resulting promotionalist view is implausible for two reasons. First there are cases where A has a desire-based reason to $\varphi$ even though A's $\varphi$ ing is not a sufficient means to the realisation of $p$. Bradley's going to the party is not a sufficient for him to strut his stuff because the dance floor may be too crowded, yet he still has a desire-based reason to go so long as there is a significant chance that the dance floor will not be overcrowded. Second, there are cases where A has a desire-based reason to $\varphi$ even though A's $\varphi$ ing is not a necessary means to the realisation of $p$. Bradley's going to the party is not necessary for him to strut his stuff if there are other dancing venues available, yet he still has a reason to go there (see Schroeder 2007: 11112).

${ }^{5}$ What I am calling motivationalism is close to the view sometimes referred to as reasons internalism, expressed by Shafer-Landau (2003: 165) as the view that 'Necessarily if A has reason to $\varphi$ at $t$ then she can be motivated 
Here $\mathrm{F}$ is an area of motivational concern such as a desire for one's own pleasure (Goldman 2009: 38), and 'if rational' is defined in terms of relevant information and coherence of desires (Goldman 2009: 51-6, compare Williams 1981). Further, to say that A is motivated to do $\varphi$ is not to say that A will $\varphi$, but only that A will $\varphi$ absent conflicting motivations (Goldman 2009: 35-36). So suppose struting his stuff gives Bradley great pleasure and that Bradley desires pleasurable sensations. On Goldman's view, Bradley has a (hedonic) reason to go to the party because he is pleasure-minded and, because of that, if relevantly informed and coherent in desire, would be motivated by awareness of the fact that there is dancing at the party to go to the party.

On both views, Bradley's desire grounds a reason to go to the party. On the promotionalist view it does so because going to the party is one way to promote the object of that desire. On the motivationalist it does so because it makes it the case that Bradley would be motivated to go to the party, if rational.

\section{Why this Debate Matters}

Even granting the Humean premise that some reasons are grounded in desires, why should we be concerned about the debate between promotionalism and motivationalism? I give two reasons. There may be more.

First, promotionalism and motivationalism generate different extensions for the complex predicate '...is a reason for...'. Consider Schroeder's example of Nate (2007: 33) Nate loves surprise parties, but hates it when the surprise is pre-empted. There is a surprise party now waiting for Nate at his home. According to promotionalism, the fact that there is a surprise party waiting for Nate is a reason for Nate to return home, because this fact helps explain why Nate's returning home will promote his desire to be surprised (this desire, we may assume, is part of Nate's love for surprises). According to motivationalism, the fact that there is a surprise party waiting for Nate is not a reason for Nate to return home, because

to $\varphi$ at $\mathrm{t}^{\prime}$. There are two reasons why I introduce the new terminology. First because reasons internalism is expressed by a conditional whereas motivationalism employs a biconditional. Second because there is an existing debate concerning whether reasons internalism is compatible with non-desire-based views of reasons (see, for example, Korsgaard 1986) whereas, as I understand it, motivationalism is a view about how reasons are grounded in desires. 
were Nate to recognise this fact he would not be motivated by it to return home, since that very recognition would spoil the surprise. Thus promotionalism and motivationalism disagree whether Nate has a reason to return home. In the next section I will argue that there is a further class of cases where promotionalism and motivationalism disagree over the reasons there are, and that in these further cases motivationalism has the upper hand. I will return to the issue of what the motivationalist can say about Nate in $\S 6$.

There is a more general reason to be concerned about the debate between promotionalism and motivationalism, namely that these theories offer very different views about the connection between reasons and reasoners (or, as it might be more grandly put, between reasons and agency). According to motivationalism, a reason-giving fact (such as the fact that there is dancing at the party) can only provide a reason if it is possible for an agent to recognise this fact and be motivated by it. Hence reasons - or more accurately, reason-giving facts - are for reasoning with. ${ }^{6}$ Thus motivationalism is to some extent supported by the intuitive thought that the idea of a reason-giving fact that no practical reasoner could recognise as a reason-giving is as implausible as the idea of an undetectably funny joke (see Lillehammer 2003). According to promotionalism, by contrast, a fact can provide a reason when there is no possibility of that fact being recognised by the person whose reason it is, and hence with no possibility of the agent being moved by, and acting in light of, that fact. According to promotionalism, reason-giving facts are still connected to motivation in so far a fact's status as reason-giving depends on desires and desires are motivating states, motivation by which counts as acting for reasons (Schroeder 2007: 167). But it is not the case that for all reason-giving facts it must be possible for the agent whose reasons they provide to be motivated by recognition of that very fact. Reasons-giving facts are not necessarily for reasoning with. Rather, on the promotionalist view, reason-giving facts are primarily explanatory: they are bits of the world that explain why a certain action promotes a certain end (where 'explanation' is a metaphysical not epistemic notion - see Schroeder 2007: 29 n.12).

\footnotetext{
${ }^{6}$ Here and elsewhere I distinguish between the reason-relation expressed by the complex predicate ' $r$ is a reason for A to $\varphi$ ' and the reason-giving fact (or true proposition) $r$. Actual usage of the term 'reason' is unfortunately ambiguous on this and many other scores.
} 
According to motivationalism, therefore, reason-giving facts are restricted to those facts that can be brought within an agent's practical deliberative sphere. According to promotionalism there is no such restriction. On the former view ideal practical reasoners are necessarily cognisant of the facts that provide their reasons, on the latter they are not. Thus these two views generate very different views about the connection between reasons and (ideal) practical reasoners.

\section{A Problem for Promotionalism: Reasons to Perform Physically Impossible Actions}

Which view should we prefer? Schroeder gives some objections to motivationalist views (2007: 165-8) and I will consider these below (§6). But there is at least one way in which motivationalist views are preferable: promotionalist views entail that there are reasons to perform physically impossible actions whereas motivationalist views entail that there are no such reasons.

Consider Bob, the lovable eccentric. Bob desires to be the first human to reach the moon unaided by technology. Now, you are much more likely to reach the moon unaided if you can leave the Earth's atmosphere unaided (once you can do that, you just need to leave in the right direction). So the fact that the moon is outside the Earth's atmosphere explains why leaving the Earth's atmosphere unaided promotes (in Schroeder's sense) the end of going to the moon unaided. ${ }^{7}$ So, by Schroeder's promotionalist account, the fact that the moon is outside the Earth's atmosphere gives Bob a reason to leave the Earth's atmosphere unaided. Such an action is, of course, physically impossible. For precision, we can define an action as physically impossible for an agent when there is no nomologically and historically accessible possible world in which the agent performs the action, where a possible world is nomologically and historically accessible iff. its laws of nature and its past are the same as those of the actual world (see Streumer 2007: 353). So Bob has a reason to perform a physically impossible action.

By contrast, consider what Goldman's motivationalism says about Bob. Bob is 'going-to-the-moon-unaided' minded. But it is not the case that Bob, if rational, would be

\footnotetext{
${ }^{7}$ Other views of the 'promotion' relation may not have this consequence, but I have already argued that the resulting promotionalist views are implausible for other reasons - see note 4.
} 
motivated by recognition of the fact that the moon is outside the Earth's atmosphere to leave the Earth's atmosphere unaided. Bob would not be motivated to leave the Earth's atmosphere unaided because (according to Goldman's account of motivation) to be motivated to $\varphi$ is to $\varphi$ absent conflicting motivations, and even absent conflict motivations Bob will not leave the Earth's atmosphere unaided (because it is physically impossible for him do so). Thus, on Goldman's account, Bob has no reason to leave the Earth's atmosphere unaided.

Although the preceding paragraph employs Goldman's own view of motivation, it is important to note that on any plausible account of what it is for an agent to be motivated to $\varphi$, Bob will not be motivated to leave the Earth's atmosphere unaided in a way which, according to the motivationalist account, is necessary for the existence of a corresponding reason. On a strong view, 'being motivated to $\varphi$ ' is a success term: an agent is motivated to $\varphi$ iff. the agent $\varphi$ 's. On this view, Bob cannot be motivated to leave the Earth's atmosphere unaided because Bob physically cannot leave the Earth's atmosphere unaided. ${ }^{8}$ Hence according to motivationalism and the strong view of motivation, Bob has no reason to leave the Earth's atmosphere unaided.

On moderate views, being motivated to $\varphi$ is a conditional success term. One moderate view is Goldman's view that an agent is motivated to $\varphi$ iff. absent conflicting motivations, the agent $\varphi$ 's. We have already seen that on this view Bob can have no motivation to leave the Earth's atmosphere unaided and hence no reason to do so. Another moderate view holds that an agent is motivated to $\varphi$ iff. absent conflicting and confounding motivations, the agent $\varphi$ 's. A confounding motivation is a recognisable psychological impairment that undermines the efficacy of an otherwise efficacious motivation. Clinical depression is perhaps the best example of a confounding motivation. On this view too, Bob can have no motivation to leave the Earth's atmosphere unaided, because even absent conflicting and confounding motivations Bob will not leave the Earth's atmosphere unaided. Once again, therefore, on this view of motivation (and given motivationalism) Bob has no reason to leave the Earth's atmosphere unaided.

On a weak view of motivation, being motivated to $\varphi$ is not a success term at all. The most obvious version of this view holds that an agent is motivated to $\varphi$ iff. absent conflicting

\footnotetext{
${ }^{8}$ Note that, in any case, this strong view of motivation generates further problems for motivationalism when considering conflicting reasons.
} 
or confounding motivations, the agent attempts to $\varphi .{ }^{9}$ On this view Bob can have motivation to leave the Earth's atmosphere unaided insofar as he attempts (inevitably unsuccessfully) to do so. But the motivationalist who accepts this view of motivation can still resist the claim that Bob has reason to leave the Earth's atmosphere unaided. For motivationalism holds that an agent has a reason to $\varphi$ only if a suitably informed agent would be motivated to $\varphi$ if rational, and the motivationalist can plausibly claim that it is a rational constraint on agents that they do not attempt to perform physically impossible actions. ${ }^{10}$ Hence a rational Bob will not attempt to leave the Earth's atmosphere unaided, and hence given motivationalism and this weak account of motivation, will not have reason to do so.

It seems, therefore, that on all plausible views about what it is to be motivated to $\varphi$, motivationalism entails that Bob does not have a reason to leave the Earth's atmosphere unaided. Generalising from Bob's case, on motivationalist views the actions agents have reason to perform are limited to those that it is physically possible for the agent to be motivated to do when rational.

So promotionalism has a problem whereas motivationalism does not. Intuitively, Bob has no reason to leave the Earth's atmosphere unaided. Yet promotionalism seems to entail that Bob does have such a reason.

\section{Promotionalist Replies}

How might the promotionalist respond? There are several options, none of them appealing.

\subsection{First Reply}

\footnotetext{
${ }^{9}$ It is a difficult question when a particular action, say A's $\Psi$ ing, counts as A attempting to $\varphi$. An intuitive view is that A's $\Psi$ ing is an attempt to $\varphi$ just in case A performs $\Psi$ because she thinks that by $\Psi$ ing she will raise the (objective) chances of her ping. I do not know whether this view is ultimately defensible, but the point doesn't affect the current argument.

${ }^{10}$ It may also be a rational requirement that agents do not have desires for physically unobtainable ends in the first place - rational desires aim at the obtainable, perhaps. However, this is not a problem for motivationalism. If rational agents do not have desires for physically unobtainable ends, then no reasons can be based on these desires, so again Bob will have no reason to leave the Earth's atmosphere unaided.
} 
The promotionalist could perhaps respond by restricting the class of desires that generate reasons to desires for physically obtainable ends, that is, ends that obtain in some nomologically and historically accessible possible world. As the laws of nature stand, no human can reach the moon unaided, so Bob's desire that he be the first human to do so is a desire for a physically unobtainable end. On the current view, this is enough to discount Bob's desire from grounding any reasons, including a reason to leave the Earth's atmosphere unaided.

This reply is untenable, for two reasons. ${ }^{11}$ First, on the promotionalist account, it is not only desires for physically unobtainable ends that can ground reasons to perform physically impossible acts. Desires for physically obtainable ends can ground such reasons as well. Consider Caterina. Caterina, an American citizen, desires to become President of the United States. This end is physically obtainable. One way to make the obtaining of this end more likely is for Caterina to use advanced telepathy to plant an intention to vote for her in the mind of every eligible voter. So the fact that advanced telepathy would change voters' preferences helps explain why Caterina's using advanced telepathy would promote the object of her desire to be President. Thus, according to promotionalism, Caterina has a reason to use advanced telepathy. Advanced telepathy is physically impossible. So Caterina, like Bob, has a reason to perform a physically impossible action. Unlike Bob, the reason is grounded in a desire for a physically obtainable end. Generalising, according to promotionalism not only can desires for physically unobtainable ends generate reasons to perform physically impossible actions, but desires for physically obtainable ends can generate reasons to perform physically impossible actions which promote those ends. ${ }^{12}$ (This example also undermines another possible promotionalist reply, which is to restrict the class of reason-generating

\footnotetext{
${ }^{11}$ A third reason is that Schroeder, the leading proponent of promotionalism, explicitly rejects Humean views that restrict the class of actual desires that ground reasons. See Schroeder 2007: 84-87.

${ }^{12}$ What does motivationalism say about Caterina? That depends on what Caterina can be motivated to do (if rational) which in turn depends on one's view of what it is to be motivated to $\varphi$ (see $\$ 2$ ). On moderate views of motivation, Caterina can only be motivated to $\varphi$ if she would $\varphi$ absent conflicting or confounding motivations. On such views Caterina can have reason to walk the streets distributing leaflets, or to put out a negative campaign advertisement, but cannot have reason to become President (since conflicting and confounding motivations are not the only barrier to becoming President). On weak views of motivation, Caterina can have reason to become President, insofar as she will (absent conflicting and confounding motivations) attempt to do so. If one finds it obvious that Caterina has a reason to become President and wants to maintain motivationalism, then this mitigates in favour of an account of motivation weaker than Goldman's.
} 
desires to those that would survive some deliberative process, such as cognitive psychotherapy or reflective equilibrium (see Brandt 1979 and Lillehammer 2000 for discussion). This suggestion has its own intrinsic difficulties (see, for example, Schroeder 2007: 86) but in the present context it doesn't solve the problem. For whatever desired ends survive this process there will still be physically impossible actions that promote these ends, which, according to promotionalism, the agent would have reason to perform.)

The second reason this reply is untenable is because it is not the case that desires for physically unobtainable ends fail to ground any reasons. What they fail to ground is reasons to perform physically impossible actions. Bob, for example, has reason to investigate the possibilities of unaided human flight (whereupon, of course, he will be disappointed). This reason is based on his desire for a physically unobtainable end, namely the desire that he be the first human to reach the moon unaided. So it is not the case that promotionalists can exclude desires for physically unobtainable ends from the class of desires that generate reasons.

\subsection{Second Reply}

A second possible reply from the promotionalist would be to restrict the class of actions that agents can have reason to perform to those that are physically possible. This would certainly solve the problem, but it is also ad hoc. Bradley's going to the party promotes his desire to dance. Bob's leaving the atmosphere unaided promotes his desire to reach the moon unaided. The relation between the action, desire and agent is in these cases the same (the action promotes the desire of the agent), and yet, on the present promotionalist view, in the first case this relation constitutes a reason-relation and in the second case it does not. Promotionalists need to give independent motivation for this division. This point can also be made in light of the previous discussion about the relations between reasons and practical reasoners $(\S 2)$. According to the promotionalist, reasons are not primarily for agents to reason with, rather they are primarily explanatory: bits of the world that explain why a (non-actual, hypothetical) action promotes a certain end. This worldly explanatory relation obtains regardless of whether the particular action that promotes a particular end is within the bounds of physical possibility. Thus the promotionalist conception of reasons cannot justifiably limit them to 
reasons to perform physically possible actions. [[[ADD HERE: Motivationalists can, whereas promotionalists cannot, explain why 'reason' entails ‘can' - see slides]]]

\subsection{Third Reply}

A third reply on behalf of promotionalism runs as follows. ${ }^{13}$ Any theory of normative reasons must allow for the preferability of performing, or attempting to perform, efficacious courses of action over inefficacious courses of action. Consider Bob. Although it is true that leaving the Earth's atmosphere unaided promotes the end of reaching the moon unaided (in that the former makes the latter more likely), it is not true that attempting to leave the Earth's atmosphere unaided promotes the same end. Any attempt by Bob's to leave the Earth's atmosphere unaided would leave the chances of his reaching the moon unaided where they are, at more-or-less zero. So, according to promotionalism, Bob has no reason to attempt to leave the Earth's atmosphere unaided. From here, this reply can be developed in two ways. First, the promotionalist might claim that agents can have reason to $\varphi$ even if they have no reason to attempt to $\varphi$. On this view, Bob has reason to leave the Earth's atmosphere, but no reason to attempt to do so. Second, the promotionalist might claim agents can have reason to $\varphi$ only if they have reason to attempt to $\varphi$. On this view, the fact that Bob has no reason to attempt to leave the Earth's atmosphere unaided entails that he has no reason to leave the Earth's atmosphere unaided, and thus the supposed problematic consequence of promotionalism is avoided.

The first way of developing this reply doesn't address the problem posed, since it still admits that Bob has reason to leave the Earth's atmosphere unaided (though denies that he has reason to attempt to do this). This conclusion, in itself, is implausible. Further, as I explain below, its implausibility can be independently supported (see §4.4).

The second way of developing this reply represents a significant modification of the promotionalist account. It claims that agents can have reason to $\varphi$ only if they have reason to attempt to $\varphi$. Since, according to the original promotionalist account, agents will have reason

\footnotetext{
${ }^{13}$ Thanks to an anonymous referee for suggesting this reply.
} 
to attempt to $\varphi$, just in case their attempting to $\varphi$ promotes some desired object $p$, this modified promotionalist view can be expressed as follows:

For all propositions $r$, agents $\mathrm{A}$ and actions $\varphi, r$ is a reason for $\mathrm{A}$ to $\varphi$ if and only if (i) there is some $p$ such that A has a desire whose object is $p$, and the truth of $r$ is part of what explains why A's doing $\varphi$ promotes $p$, and (ii) A's attempting to $\varphi$ promotes $p .^{14}$

This modified account needs to be supplemented with a view on what it is to 'attempt to $\varphi$ '. But putting that complication aside, this modified promotionalist view is implausible when applied to simple cases. Consider Unfortunate Bradley. Like Bradley, Unfortunate Bradley desires to dance and there is a party with dancing nearby. Unfortunately, Unfortunate Bradley is tied to a chair, unable to move. The bonds are impossible for Unfortunate Bradley to break; he must wait and hope for a saviour. Unfortunate Bradley has a reason to go to the party, more precisely the fact that there is dancing at the party is a reason for him to go there. Yet any attempt by Unfortunate Bradley to go to the party would not (in his present circumstances) promote the end of his dancing. Moreover, the justification that promotionalists have for thinking that Unfortunate Bradley has reason to go to the party is the very same sort justification they had for thinking that Bradley has a reason for going to the party, namely that doing so promotes a relevant desire (to dance). Unfortunate Bradley is therefore a counterexample to the modified form of promotionalism - he satisfies the lefthand-side of the biconditional but not clause (ii) of the right-hand-side. Further, counterexamples with a similar structure as Unfortunate Bradley are commonplace. I have a reason to write a philosophical masterpiece, but after five consecutive hours of teaching, to attempt to do so would be counter-productive. Caterina has reason to persuade voters to back her Presidential campaign, but in her present foul mood to attempt to do so is more likely to deter voters. And so on. In many cases, therefore, agents have reason to $\varphi$ even when their attempting to $\varphi$ doesn't promote the same goal that $\varphi$-ing does. Hence we should reject modified promotionalism.

Hence, whichever way it is developed, the third reply fails.

${ }^{14}$ This is a rough expression of modified promotionalism because clause (ii) 


\subsection{Fourth Reply}

Finally, the promotionalist could bite the bullet and accept that agents have reasons to perform physically impossible acts. Although Schroeder explicitly rejects this view (2007: 53) it may be defensible.

Indeed in a distinct but closely related context, bullet-biting is the approach Schroeder takes (2007: 92-97). Schroeder considers the 'Too Many Reasons' objection to Humean theories (including promotionalism), namely that they generate reasons to act when intuitively there are none. For example:

...Aunt Margaret wants to reconstruct the scene depicted on page 78 of the November 2001 Martha Stewart Living catalogue on Mars. In order to do this she needs to construct a Mars-bound spacecraft - for no one is going to give her one...[But] the Humean theory is committed to claiming that there is some reason fro Aunt Margaret to build her spacecraft. And intuitively this is...not the right result. According to a very natural intuition, there is simply no reason for Aunt Margaret to build her spacecraft. (Schroeder 2007: 84)

Schroeder bites the bullet about Aunt Margaret's reason. He also concludes that such bulletbiting is palatable because intuitions in the form of negative reason existentials ('There is no reason for A to $\left.\varphi^{\prime}\right)$ are demonstrably unreliable in particular cases (2007: 93-94). Further, Schroeder claims, this unreliability can be explained insofar as we typically make reason statements for the purpose of guiding action, and so it makes conversational sense not to mention (and even to deny the existence of) relatively light-weight reasons such as Aunt Margaret's (2007: 94-97). In short, the argument is that silly reasons like Aunt Margaret's are easily outweighed by other reasons, and this explains why we tend to deny their existence given that the action-guiding purpose of making reason statements is generally only served by mentioning relatively weighty reasons.

Perhaps Schroeder's response to Aunt Margaret's reason may be applied to Bob's reason. If Bob's reason to leave the Earth's atmosphere unaided is relatively lightweight, then we can explain why we have the misleading intuition that Bob has no such reason in terms of the conversational demands on making statements about reasons. On this view, Bob does have a reason to leave the Earth's atmosphere unaided, but we can explain why we tend not to mention it. The bitten bullet is thereby made more digestible. 
This reply faces many difficulties. First, it relies on the claim that reasons to perform physically impossible actions, such as Bob's, are always relatively lightweight. This in turn requires an account of the (relative) weight of reasons. Moreover, on a plausible account, the weight of a desire-based reason to $\varphi$ is proportional both to the strength of the desire that grounds it and to the likelihood that ping will promote the object of that desire. Schroeder (2007: 98) calls this view proportionalism. Proportionalism creates problems in the current context. Suppose that Bob's desire to be the first human to reach the moon unaided is very strong. Given promotionalism and proportionalism, Bob's reason to leave the atmosphere unaided will also be relatively strong, that is, not easily outweighed by other reasons. If so, Schroeder's explanation of why we tend to not to mention such reasons cannot work. Hence if promotionalists are bullet-biters about Bob's reason, they cannot accept proportionalism as a view of the (relative) weight of reasons. (Note that this particular problem would not worry Schroeder, who in any case rejects proportionalism, see 2007: 99-101.)

Second, the bullet-biting reply faces the problem that the claim that there are no reasons to perform physically impossible acts is not merely intuitive in itself, such that it might be explained away by noting the conventions of conversational assertion that Schroeder notes. Rather there are independent arguments for thinking this claim true. Streumer (2007) gives two such arguments. ${ }^{15}$ The first is that the claim that there are no reasons to perform physically impossible acts is the best explanation of why inanimate objects such as tables and chairs do not have reasons (2007: 362). The second is that this claim is the best explanation of why deliberation about reasons tends not to result in agents trying to perform physically impossible acts (2007: 365). Streumer's example here is illuminating. Suppose we grant the bullet-biting response and accept that we can have reason to perform physically impossible acts. If this is so, then it seems plausible that the thing we have strongest reason to do is to travel back in time and prevent the Crusades, slavery and the two World Wars. (This reason is strong, the thought goes, because of the immense amount of suffering involved in these events.) Further, it is plausible to think that when agents rationally deliberate, they should end up attempting to do the thing they have strongest reason to do. Hence, if there are reasons to perform physically impossible actions then 'rational deliberation will almost always result in

\footnotetext{
${ }^{15}$ Streumer actually gives three arguments for thinking that there are no reasons to perform physically impossible actions, but since his first argument is entirely based on intuitions about what reasons there are, it provides no dialectical weight here.
} 
a person pointless trying to perform actions that he or she cannot perform' (Streumer 2007: 366). And since rational deliberation should not have such pointless results the best explanation of this is that there are no reasons to perform physically impossible actions. Note in particular that this objection to the bullet-biting response doesn't require assuming a particular theory of the weight of reasons, only that if there are reasons to perform physically impossible actions, then the reason to travel back in time to prevent the Crusades, slavery and the two World Wars will be a comparatively weighty reason. This claim seems to be a pretheoretical desideratum on a theory of the weight of reasons rather than the consequence of any particular such theory. ${ }^{16}$ Thus this objection to the bullet-biting response is much stronger than the first (which assumed proportionalism as a theory of the weight of reasons).

To Streumer's arguments for the claim that there are no reasons to perform physically impossible actions we can add another, also concerning deliberation. When an agent is deliberating well, the sort of thing she should be deliberating about are her reasons. (This 'deliberative constraint' is accepted by Schroeder at 2007: 26). Hence in an ideal case where an agent has ample time to consider all her reasons, an agent should consider all her reasons, no matter what their relative weight. But if there are reasons to perform physically impossible actions, then given ample time, Caterina should consider, among other things, all the physically impossible ways in which she could promote her goal of becoming President. But this is absurd. The best explanation of what prevents Caterina deliberating about these physically impossible ways of promoting her goal is not that she hasn't sufficient time to consider them, but that they are physically impossible and that one cannot have reasons to perform physically impossible actions. Thus once again the claim that there are no reasons to perform physically impossible actions is not merely intuitive on its face, but independently supportable.

I conclude that the bullet-biting response is not tenable as a defence of promotionalism. There are good independent arguments for thinking that there are no reasons to perform physically impossible actions (arguments, that is, independent of the mere intuitive plausibility of this claim). The bullet-biting response flies in the face of such arguments.

\footnotetext{
${ }^{16}$ Schroeder agrees that an account of the weight of reasons needs to capture the significant weight of sufferingbased reasons such as this one (2007: 141-43).
} 


\section{Interim Conclusion}

Promotionalism is implausible insofar as it entails agents can have reasons to perform physically impossible actions. Further, if promotionalism is true, agents will have such reasons even if the desires that generate them are for physically obtainable ends. Motivationalism, by contrast, entails that there are no such reasons. This is some reason to prefer the latter as the correct account of the way in which desires explain some reasons for action.

\section{Problems for Motivationalism}

None of this is to say, however, that motivationalism does not face its own difficulties, even granting the Humean assumption that some reasons are based on desires. In this final section I consider and reject three apparent counterexamples to motivationalism provided by Schroeder.

First, there is the case of Nate already mentioned (\$2). Intuitively, Nate has a reason to return home. As Schroeder puts it: 'There is certainly something that God would put in the 'pros' column in listing pros and cons of Nate's going [home]' (2007: 165). Yet according to motivationalism Nate has no such reason, because he cannot be motivated to go home by recognition of the fact that a surprise awaits. So although there is something to be said for Nate's going home, it is not something to say to Nate.

The motivationalist can respond by doing his own bit of rapid-projectile mastication. ${ }^{17}$ Nate has no reason to return home. However, the motivationalist can add, it would still be good-for-Nate if he returned home, and as such this is something that it is advisable for him to do. In other words, the motivationalist can accept a promotionalist account of the good-foran-agent alongside a motivationalist account of reasons. Such an account might hold that:

A's ping is good-for-A if A desires that $p$ and A's ping would promote $p .^{18}$

\footnotetext{
${ }^{17}$ Bullet-biting.

${ }^{18}$ For present purposes the motivationalist need only accept the conditional version of this claim, although a biconditional might also be defensible. Also, for isomorphism to Schroeder's view, the view could be stated as:
} 
Further, the motivationalist might hold that A's ping is advisable if A's ping is good-for-A. Hence the motivationalist can accept that Nate's returning home is both good-for-Nate and something to advise him to do, whilst denying that it is something that Nate has reason to do. Further, it is highly doubtful that our intuition about Nate's case is fine-grained enough to distinguish between this set of claims (that is: that going home is good-for-Nate, advisable but not something he has reason to do) and the promotionalist claim that Nate has reason to go home. Thus the motivationalist can argue that his view captures all that needs to be captured from our intuitions about Nate.

The second problem-case for the motivationalist is that of 'massive and decisive contrary reasons' (Schroeder 2007: 166). Consider Joel. Joel has very many strong and stable desires that are promoted by him staying in Los Angeles. However, he has one desire that is promoted by leaving Los Angeles and going to Madison (in Schroeder's example, this is the desire to eat a particular type of ice-cream that can only be purchased in Madison). According to Schroeder, Joel has no motivation whatsoever to go to Madison, and yet still has some (albeit relatively lightweight) reason to go there, contradicting motivationalism.

This case is not a counterexample to any version of motivationalism that accepts a moderate or weak account of motivation (see $\$ 3$ ). According to moderate accounts to say that A is motivated to $\varphi$ is to say that A would $\varphi$, absent conflicting and confounding motivations. This is true in Joel's case: absent all the other motivations that tie him to Los Angeles and absent any confounding motivations, Joel would go to Madison. According to weak accounts of motivation to say that $\mathrm{A}$ is motivated to $\varphi$ is to say that, absent conflicting and confounding motivations, A would attempt to $\varphi$. This is also true in Joel's case: absent all the motivations that tie him to Los Angeles and absent any confounding motivations, Joel would attempt to go to Madison. Thus versions of motivationalism that accept moderate and weak accounts of motivation can accept the intuition that Joel has reason to go to Madison.

Schroeder in fact considers something like this response and rejects it. He claims:

$r$ is a good-for-A-making feature of A's $\varphi$ ing if (and only if) there is some $p$ such that A desires that $p$ and the truth of $r$ is part of what explains why A's doing $\varphi$ promotes $p$. 
It is not that I don't think that Joel can be motivated to move to Madison...If you first got Joel to stop caring about all of these things, then I have no doubt that you could motivate him to move to Madison. But if you are allowed to change all those things about him in order to motivated him to act, then I don't know what you couldn't motivated him to do...Asking what Joel would do if we removed all these things is like asking what he would do if he had a totally different psychology. If we are allowed to do that, then I'm worried that it will trivialize [motivationalism]. (2007: 166-67)

But we can distinguish between the things that Joel would do (or attempt to do) given the absence of certain actual elements of his psychology and the things that Joel would do (or attempt to do) given the addition of certain non-actual elements of his psychology. Although appealing to the second set of actions trivializes motivationalism, appealing to the first does not (and arguably reflects the view of actual motivationalists such as Goldman).

Schroeder's final counterexample to motivationalism is that of amoralists who persistently fail to be moved to perform morally required actions (such as helping a stranger in need) but who still, intuitively, have reason to perform those actions. Such cases are unlikely to unseat motivationalism, however, since it can be plausibly doubted first, whether amoralists do have reason to be perform morally required actions (this is consistent with claiming that they morally ought to perform these actions) and second whether amoralists really do lack motivation to perform morally required actions (it may be that amoralists have motivations that conflict with or confound motivations to perform morally required actions). ${ }^{19}$ More generally the problem with utilising this argument in the current context is that the issues of (i) what actions we are morally required to perform (ii) whether moral requirements provide reasons for action and (iii) whether amoralists suffer some recognisable motivational defect, are all issues of serious contention in the existing literature. One cannot therefore rest an argument against motivationalism on the mere intuitive acceptability of the

\footnotetext{
${ }^{19}$ For doubts of the first kind see Foot 1972 and Williams 1981. For discussion see Brink 1992.
} 
claim that amoralists are subject to reason-providing moral requirements but lack relevant motivation. $^{20}$

\section{Conclusion}

I have argued that promotionalism is implausible insofar as it entails that agents can have reasons to perform physically impossible actions. Bob's reason is one example, Caterina's another. Not only is this conclusion counter-intuitive in itself, there are good arguments against it. Motivationalism, on the other hand, entails that there are no reasons to perform physically impossible actions. Further, motivationalism can deal with apparent counterexamples, such as Nate and Joel. Hence Humeans should prefer motivationalism as an account of the way in which reasons are grounded in desires.

\section{References}

Alverez, M. 2010. Kinds of Reasons. Oxford: Oxford University Press.

Brandt, R. 1979. A Theory of the Good and the Right. Oxford: Oxford University Press.

Brink, D. O. 1992. 'A Puzzle About the Rational Authority of Morality', Philosophical Perspectives 6: 1-26.

Goldman, A. 2009. Reasons from Within. Oxford: Oxford University Press.

Korsgaard, C. 1986. 'Skepticism About Practical Reason', Journal of Philosophy 83: 5-25.

Lillehammer, H. 2000. 'The Doctrine of Internal Reasons'. Journal of Value Inquiry 34: 507516.

Lillehammer H. 2003. 'The Idea of a Normative Reason' in P. Schaber \& R. Huntelmann, eds. Grundlagen der Ethik. Frankfurt: Ontos Verlag 41-65.

\footnotetext{
${ }^{20}$ Note also that accommodating moral reasons, such as they are, seems to be a problem for all Humean theories of reasons, and therefore not a specific problem for motivationalism. For Schroeder's promotionalist account of moral reasons see his 2007: 102-122. I argue elsewhere that this account fails.
} 
Schroeder, M. 2007. Slaves of the Passions. Oxford: Oxford University Press.

Setiya, K. 2004. 'Hume on Practical Reason' Philosophical Perspectives 18: 365-389.

Shafer-Landau, R. 2003. Moral Realism. Oxford: Oxford University Press.

Streumer, B. 2007. 'Reasons and Impossibility' Philosophical Studies 136: 351-384

Williams, B. 1981. 'Internal and External Reasons' in his Moral Luck. Cambridge:

Cambridge University Press. 